\title{
Foreword: A Velvet Revolution in Fascism
}

Fascism is now in its fifth year, and has established itself as the world's foremost journal for Anglophone articles on fascism. In the summer of 2015 it was decided at a meeting of editors and publishers that the readership base was sufficiently strong for it to become the journal of a newly formed Association for Fascist Studies. Apart from hosting a website, running an annual conference, and providing a forum, information centre and virtual 'home' for specialists contributing to fascist studies, such an association will also have the advantage of enabling the journal to run without charging contributors publication fees.

After a lot of work behind the scenes, plans are well advanced for the Central European University in Budapest to host the Association administration and website, and for the Association's first director to be Professor Constantin Iordachi. We are thankful to Constantin for the effort this has demanded, and to his Faculty for their generosity. The next issue will contain more detailed information about the inaugural conference, subscriptions and membership. Meanwhile we ask all those reading this issue to consider encouraging their institution to become members of the institution on a faculty or individual level when it is launched.

At the same time we are pleased to announce that Professor Nigel Copsey will continue with his editorial role but will be joint editor with our new board member, Dr Graham Macklin (Teesside University, U K). Please feel encouraged (or encourage colleagues) to contribute to Fascism, either in the form of articles or conference reports on conferences you have attended. And prepare yourself for the rebirth of Fascism in a new order.

The Editors 